\title{
French minister outlines research proposals
}

Paris. France's National Assembly is this week scheduled to debate science for the first time since 1982. But rather than addressing a government-endorsed white paper setting out a new national strategy for research, as some had anticipated, the assembly will discuss a report from François Fillon, the minister for higher education and research, outlining his plans for the future of the research system.

The climb-down has been partly prompted by resistance from scientists to the final report of the government's six month national 'consultation' on research (see Nature 368, 675; 1994), which was intended to form the basis of the Assembly debate.

But following protests from the research community and a subsequent flurry of discussions with research leaders, the report has been virtually rewritten from scratch over the past eight weeks. Observers say the new version shows that Fillon appears to have listened to the views of the research community, and abandoned some of his more radical ideas.

As such the new report is likely to be given a warmer welcome by scientists. But many of those previously sceptical about the government's commitment to science have become even more so since the finance $\mathrm{min}$ istry froze FF900 million (US\$153 million) of the budget for research and development (R\&D) last week (see Nature 369, 511; 1994).

In a bid to minimize the embarrassment this has caused, Fillon was expected to announce this week that he has secured an immediate reprieve of around FF220 million of the frozen money from the finance ministry. He is also said to have gained assurances from the prime minister, Edouard Balladur, that the rest of the money will be unfrozen before the end of the year.

But the National Assembly will still have relatively little to chew over. For example, it is unlikely to contest a vague promise to increase spending on French R\&D from 2.4 to 2.8 per cent of the gross national product - to match the current level of the United States and Japan - by 2005.

Fillon will also propose that his ministry adopts a national research strategy to be built on reviews of strategic areas by a new permanent body, the Committee for Strategic Orientation. This will be made up of scientists, economists, industrialists and representatives from other fields. Appointed by the prime minister, it is intended to respond to requests from the ministry, and produce reviews on its own initiative.

But the concrete impact of the strategy remains unclear. Its remit will be to coordinate large multidisciplinary programmes, big equipment, applied research and technology transfer among research organizations, universities and companies. But it will not set priorities for fundamental research, a goal which the paper describes as "illusory".

Fillon is also proposing that the National Assembly should review research strategy annually, on the eve of the vote on the research budget. This may raise the political profile of science, but risks being more of a rubber stamp than a stimulant of debate.

Many of the concrete measures expected to be proposed by Fillon this week have already been aired before the national consultation. His ministry, for example, has already agreed to enter into five-year contracts with the research organizations in a bid to fix strategic objectives and to specify the resources allocated to achieving them

Fillon: promising

university posts.

The paper calls for a new generation of grandes programmes (major programmes) in biotechnology, electronics, computing, new materials and other areas of economic importance. This is the long predicted consequence (see Nature 367, 8; 1994) of the end of the Cold War, which has reduced the political and strategic importance of the existing four big programmes, namely on space, aeronautics, telecommunications and nuclear technology, on which France spends more than half its research budget.

The biggest change is perhaps the paper's proposals to promote industrial spending on research. Until now, a few large companies have obtained the lion's share of research funding within the big programmes, but small and medium-sized companies (SMEs) will now get much more. (One "explosive" proposal, say officials, is to

require big companies to subcontract 20 to 40 per cent of state research funding out to SMEs).

Research funding of large companies is often little more than a state subsidy, claims one French official. By diverting money to SMEs, and setting up better evaluation procedures, the government hopes more funding will find its way into laboratories, he says, leading to an overall increase in $R \& D$ spending by industry.

Other proposals designed to encourage SMEs to do more research include collecting various funding opportunities and administrative procedures at a "single cashpoint", establishing databases to help SMEs identify collaborators in public research agencies, and pressing for creation of a "Euro-NASDAQ" to increase availability of risk capital.

Fillon's most revolutionary proposal is to increase the mobility of scientists by creating a system of postdoctoral researchers. France is proud of its policy of lifetime employment, and is reluctant to create a population of researchers on short-term contracts. The Academy of Sciences will probably be asked to suggest how best to introduce the scheme.

A further incentive to mobility is a proposal to create one new university job for every transfer of staff from the research organizations (or one job for three transfers in well-staffed universities). Industrial and teaching experience would also be made a criterion for promotion.

Responding to demands from researchers, Fillon was also expected to promise to recruit new research staff at a rate of three per cent a year over the next decade in order to maintain a sensible age structure (more than half of France's current researchers will have retired by 2005). Priority areas, such as life sciences, would be allowed to recruit at higher rates.

Declan Butler

\section{Compromise reached on bioethics bill}

Paris. The French Senate and National Assembly have agreed a compromise on three bioethics bills, clearing the way for France to become the first country in the world to introduce comprehensive legislation on bioethics.

The bills were given their first reading in the National Assembly in November 1992, but last year's change in government meant that the final readings in both houses were delayed until this year (see Nature 367, 209; 1994). Both houses are likely to adopt the compromise by the end of this month, and the bills will then become law.

One of the most contentious issues has been the fate of supernumerary embryos, of which there are around 11,000 in France. The Senate wanted to forbid their destruction. The compromise allows the destruction of embryos conceived before the law comes into force, but not of those conceived afterwards. The fate of the latter will be decided in five years' time, when the bioethics laws will be revised.

The Senate had also wanted to ban the pre-implantation diagnosis of embryos conceived in vitro, in order to avoid the risk that such techniques could be used for eugenic purposes. But it has now accepted the assembly's position that such diagnosis should be allowed in cases where parents risk conceiving a child with a serious genetic disorder.

D. B. 